\title{
An optimization model for the integration of renewable technologies in power generation systems
}

\author{
Andreas Poullikkas ${ }^{1, *}$ \\ ${ }^{1}$ Electricity Authority of Cyprus, P.O. Box 24506, 1399 Nicosia, Cyprus \\ *Corresponding author. Tel: +357 22 201810, Fax: +357 22 201809, E-mail: mspoul@ucy.ac.cy
}

\begin{abstract}
In view of the expanding Renewable Energy Sources (RES) generation worldwide and in particular in European Union, it is crucial for every country to consider the cost of integrating the necessary mixture of RESE technologies in their existing and future generation systems. In this work, an optimization model for the integration of RES electricity (RES-E) technologies in power generation systems is developed. The purpose of the optimization procedure is to assess the unavoidable increase in the cost of electricity of a $g$ iven power generation system at different RES-E penetration levels. The optimization model developed uses a genetic algorithm (GA) technique for the calculation of both the additional cost of electricity due to the large penetration of RES-E technologies as well as the required RES-E levy in the electricity bills in order to fund this RES-E penetration. The above GA procedure enables the estimation of the level of the adequate (or eligible) feed-intariff (FiT) to be offered to future RES-E systems. The overall cost increase in the electricity sector for the promotion of RES-E technologies, for a given period, is analyzed taking into account factors, such as, the fuel avoidance cost, the carbon dioxide emissions avoidance cost, the conventional power system increased operation cost, etc. The applicability of the developed optimization model is applied to the small isolated power generation system of the island of Cyprus. The results indicated that in the case of $15 \%$ RES-E penetration by providing FiTs with a $10 \%$ internal rate of return the required level of RES-E levy in the electricity bills will be $0.53 € \mathrm{c} / \mathrm{kWh}$.
\end{abstract}

Keywords: Power generation, renewable energy sources, genetic algorithm, optimization

\section{Introduction}

The European Union (EU) has already tuned its energy policy into achieving maximum carbon dioxide $\left(\mathrm{CO}_{2}\right)$ emissions reduction from power generation plants. In this context, it has already set out a strategic objective of achieving at least a $20 \%$ reduction of greenhouse gases by 2020 compared to 1990 levels [1]. This strategic objective represents the core of the new European energy policy. Recognizing the positive effects of renewable energy sources (RES) technologies towards achieving this goal, the EU has taken a range of specific actions in the direction of enhancing the integration of RES in the existing European power generation system as a major step towards the reduction of global warming and climate change phenomena. Specifically, an action plan in the form of an EU Directive on the promotion of the use of energy from renewable sources [4] has been introduced by the EU whereby a target of RES share of $20 \%$ out of the gross final energy consumption of the EU has been set to be reached by the year 2020. The RES Directive [4] establishes a common framework for the promotion of energy from RES. It sets mandatory national targets for each Member State for the overall share of energy from RES in gross final consumption of energy and for the share of energy from RES in transport. Also, it lays down rules relating to statistical transfers between Member States, joint projects between Member States and with third countries, guarantees of origin, administrative procedures, information and training, and access to the electricity grid for energy from RES.

In line with the EU RES policy, each Member State must adopt a national RES action plan. The national RES action plans are expected to set out Member States' national targets for the share of energy from RES consumed in transport, electricity and heating and cooling in 2020, taking into account the effects of other policy measures relating to energy efficiency on final 
consumption of energy, and adequate measures to be taken to achieve those national overall targets. In view of the expanding RES generation in EU, it is crucial for Member States to consider the cost of integrating the necessary mixture of RES-E technologies in their existing and future generation systems up to the year 2020. For such an investigation, it is fundamental to perform an analysis of the new technical, economic and environmental status that the integration of such technologies will affect in the current and long term strategic planning of the EU generation systems expansion. The available existing software can only provide an estimate of the cost increase based on predetermined capacity factors or energy production of RES-E technologies. However, in order to perform more detail analysis and more accurate cost estimates there is a need for the implementation of an optimization model implementing unit commitment algorithms

In this work, an optimization model for the integration of RES electricity (RES-E) technologies in power generation systems on a unit commitment basis is developed. The purpose of the optimization procedure is to assess the unavoidable increase in the cost of electricity of a given power generation system at different RES-E penetration levels. The optimization model developed uses a genetic algorithm (GA) technique for the calculation of both the additional cost of electricity due to the large penetration of RES-E technologies as well as the required RES-E levy in the electricity bills in order to fund this RES-E penetration. The algorithm combines the WASP IV software [11], for optimal expansion plan for a given power generating system and the IPP v2.1 software [7] for the optimum cost of electricity produced from both conventional and RES technologies. Also, this GA procedure enables the estimation of the level of the adequate (or eligible) feed-in-tariff to be offered to future RES-E systems. The applicability of the developed optimization model is applied to the small isolated power generation system of the island of Cyprus.

In section 2, the simulation methodology and the optimization GA developed are described. In section 3, the methodology is demonstrated for the integration of RES-E technologies in the Cyprus power generation system. The conclusions are summarized in section 4 .

\section{Optimization model}

The optimization model developed uses a GA technique for the calculation of both the additional cost of electricity due to the large penetration of RES technologies as well as the required RES-E levy in the electricity bills in order to promote such penetration. A schematic diagram of the optimization flow chart is shown in Figure 1. The algorithm combines the WASP IV software [11], for optimal expansion plan for a given power generating system and the IPP v2.1 software [7] for the optimum cost of electricity produced from both conventional and RES technologies. Both have been used extensively during the past years for similar studies (e.g., [8], [10]). A brief description of simulation software follows.

\subsection{WASP IV software}

The future generation system is simulated using the Wien Automatic System Planning IV (WASP IV) software package [11], which is widely used for automatic generation planning. The WASP IV software package finds the optimal expansion plan for a given power generating system over a period of up to 30 years. The foreseen seasonal load duration curves, the efficiency, the maintenance period and the forced outage rate of each generating plant are taken into account. The objective function, which shows the overall cost of the generation system (existing and candidate generating plants), is composed of several components. The components, related to the candidate generating units, are the capital cost and the salvage capital cost. The components, which are related to both the existing and candidate generating 
units are the fuel cost, the fixed operation and maintenance costs, such as, staff cost, insurance charges, rates and fixed maintenance, the variable operation and maintenance costs, such as, spare parts, chemicals, oils, consumables, town water and sewage.

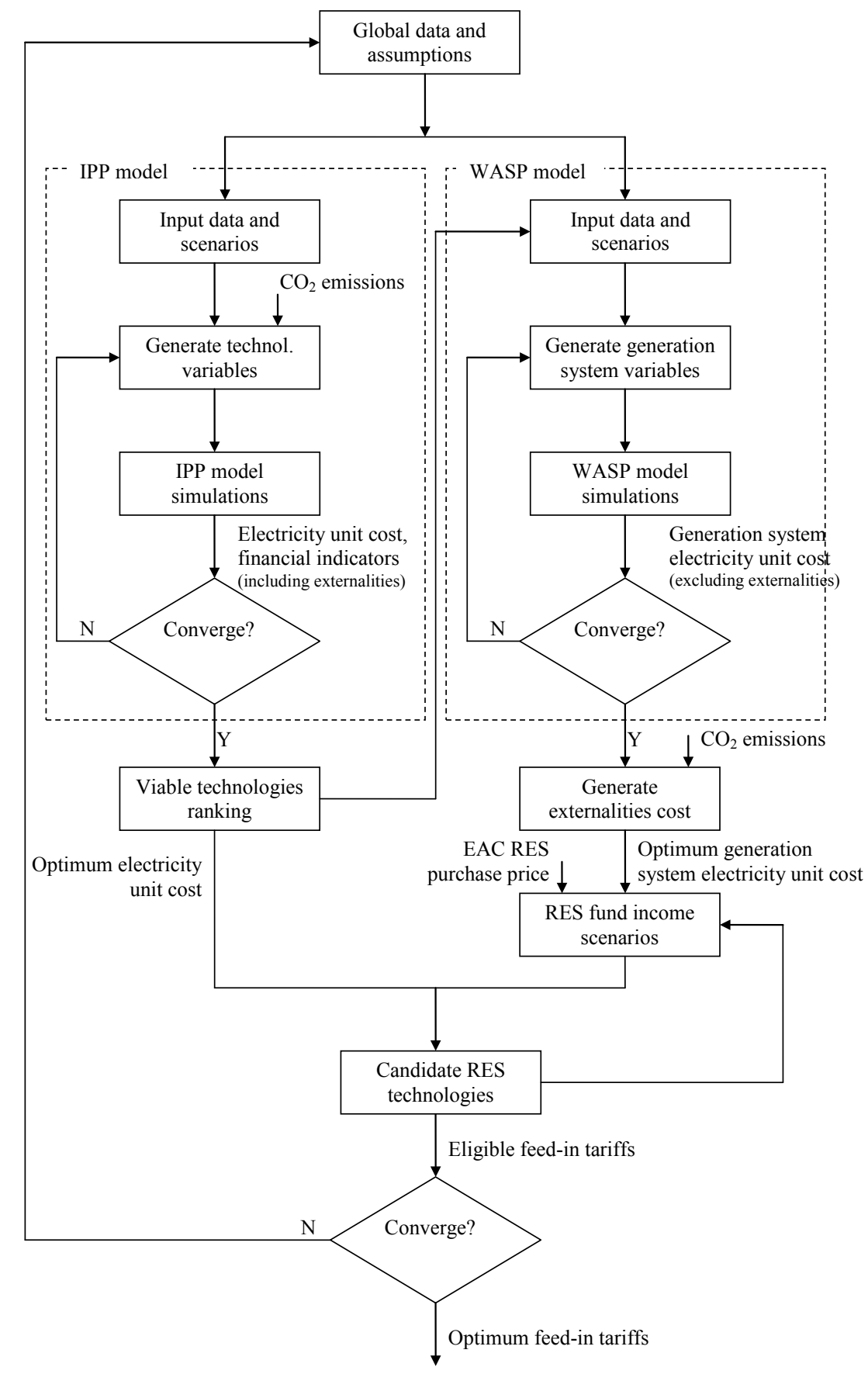

Figure 1: Flow chart of the optimization model

The cost to the national economy of the energy not served (ENS) because of shortage of capacity or interruptions is, also, taken into consideration. In the production simulation of WASP, a one-year period is divided into, at most, $12 \mathrm{~s}$ ub-periods for each of which probabilistic simulation is applied. Equivalent load duration curves in the probabilistic simulation are approximated using Fourier series. The Fourier expansion makes it computationally simple to convolve and deconvolve generating units in the probabilistic simulation. The decision of the optimum expansion plan is made by the use of forward 
dynamic programming. The number of units for each candidate plant type that may be selected each year, in addition to other practical factors that may constrain the solution is specified. If the solution is limited by any such constraints, the input parameters can be adjusted and the model re-run. The dynamic programming optimization is repeated until the optimum solution is found. Each possible sequence of power units added to the system (expansion plan) meeting the constraints is evaluated by means of a cost function (the objective function), which is composed of (a) capital investment costs, $I$, (b) salvage value of investment costs, $S$, (c) fuel costs, $F$, (d) non-fuel operation and maintenance costs, $M$, and (e) cost of energy not served, $\Phi$. Thus,

$$
B_{j}=\sum_{t=1}^{T}\left[I_{j t}-S_{j t}+F_{j t}+M_{j t}+\Phi_{j t}\right] \text {, }
$$

where, $B_{j}$ is the objective function attached to the expansion plan $j, t$ is the time in years $(1,2$, $\ldots ., T)$ and $T$ is the length of the study period (total number of years). All costs are discounted to a reference date at a given discount rate. The optimum expansion plan is the $\min B_{j}$ among all $j$. Details of the optimization algorithm implementing the above mathematical formulation can be found in [11].

\subsection{IPP v2.1 software}

In order to calculate the cost of electricity from the various RES candidate technologies each plant operation is simulated using the IPP v2.1 software [7]. The software emerged from a continued research and development in the field of software development for the needs of power industry. This user-friendly software tool can be used for the selection of an appropriate least cost power generation technology in competitive electricity markets. The software takes into account the capital cost, the fuel consumption and cost, the operation cost, the maintenance cost, the plant load factor, etc. All costs are discounted to a reference date at a given discount rate. Each run can handle 50 different candidate schemes simultaneously. Based on the above input parameters for each candidate technology the algorithm calculates the least cost power generation configuration in real prices and the ranking order of the candidate schemes. A brief description of the optimization procedure is given below. The technical and economic parameters of each candidate power generation technology are taken into account based on the cost function:

$$
\min \left(\frac{\partial c}{\partial k}\right)=\min \left\{\frac{\sum_{j=0}^{N}\left[\frac{\frac{\partial C_{C_{j}}}{\partial k}+\frac{\partial C_{F_{j}}}{\partial k}+\frac{\partial C_{O M F j}}{\partial k}+\frac{\partial C_{O M V}}{\partial k}}{(1+i)^{j}}\right]}{\sum_{j=0}^{N}\left[\frac{\frac{\partial P_{j}}{\partial k}}{(1+i)^{j}}\right]}\right\},
$$

where $\mathrm{c}$ is the final cost of electricity in $€ / \mathrm{kWh}$, in real prices, for the candidate technology $k$, $C_{C j}$ is the capital cost function in $€, C_{F j}$ is the fuel cost function in $€, C_{O M F j}$ is the fixed O\&M cost function in $€, C_{O M V j}$ is the variable $O \& M$ cost function in $€, P_{j}$ is the total electricity production in $\mathrm{kWh}, j=1,2, \ldots N$ is the periods (e.g., years) of installation and operation of the 
power generation technology and $\mathrm{i}$ is the discount rate. The least cost solution is calculated by:

least cost solution $=\min \left[\frac{\partial c}{\partial k}\right]$

During the simulations procedure the following financial feasibility indicators are calculated (a) electricity unit cost or benefit before tax (in $€ / \mathrm{kWh}$ ), (b) after tax cash flow (in $€$ ), (c) after tax NPV (net present value: the value of all future cash flows, discounted at the discount rate, in today's currency), (d) after tax IRR (internal rate of return: the discount rate that causes the NPV of the project to be zero and is calculated using the after tax cash flows. Note that the IRR is undefined in certain cases, notably if the project yields immediate positive cash flow in year zero) and (e) after tax PBP (payback period: the number of years it takes for the cash flow, excluding debt payments, to equal the total investment which is equal to the sum of the debt and equity). Details of the optimization algorithm implementing the above mathematical formulation can be found in [5], [7].

\section{RES-E integration analysis}

In this section, the above model is tested for the assessment of the cost increase of electricity by the integration of the necessary RES-E technologies mixture by 2020 in the case of the island of Cyprus. The optimization model used is based on a GA technique, for the calculation of both the additional cost of electricity due to the large penetration of RES technologies as well as the required RES-E levy in the electricity bills, in order to promote and fund such penetration.

\subsection{RES-E penetration scenarios}

Over the study horizon, the analysis examines 4 levels of RES-E penetration in the electricity sector of $10 \%, 15 \%, 20 \%$ and $25 \%$. Based on the above levels of penetration a total of 5 scenarios, regarding the future power generation expansion of the Cyprus generation system are examined. The first scenario considers the expansion of the Cyprus generation system without any RES-E technologies but only with natural gas combined cycle technologies of $220 \mathrm{MWe}$ capacity, which is considered as the BAU expansion scenario. The remaining four scenarios consider expansion with RES-E technologies. This is done in order to assess the additional electricity unit cost (compared to the BAU scenario) of the future Cyprus generation system with the expected integration of the necessary RES-E technologies mixture by the year 2020 .

In all four RES-E scenarios, the natural gas combined cycle plants of 220MWe capacity remain a candidate option for the system expansion, with the addition of four RES-E candidate technologies, namely wind, PV, biomass and CSP with 6 hour thermal storage [9], in different capacity mixtures per scenario based on (a) satisfaction of the minimum indicative trajectories for the penetration of RES-E technologies in the Cyprus power generation system as set out in [3] and [4], (b) available potential of each individual RES-E technology, (c) level of penetration of each individual RES-E technology into the grid without any technical problems, (d) RES-E capacity installation priority and (e) RES-E contribution to the power generation system capacity reserve margin. Real data have been used in the case of conventional power generation technologies and RES-E technologies technical, economic and environmental parameters. In the case of fuel prices as well as $\mathrm{CO}_{2}$ EU ETS trading cost, projections have been used in line with recent EU estimates. 


\subsection{Simulations results and discussion}

One of the measures for the promotion of the use of RES-E technologies is the feed-in tariff (FiT) measure. FiT sets a guaranteed premium price to the RES-E producer and puts an obligation on the grid operators to purchase the output. The FiT price is typically guaranteed for a long period in order to encourage investments in new RES-E plants. Therefore, in order for the FiTs, corresponding to various RES-E technologies, to become attractive, a satisfactory IRR to the RES-E producer is necessary. The optimum results concerning FiTs, with an acceptable level of IRR to the RES-E producers, of 10\% are illustrated in Figure 2.

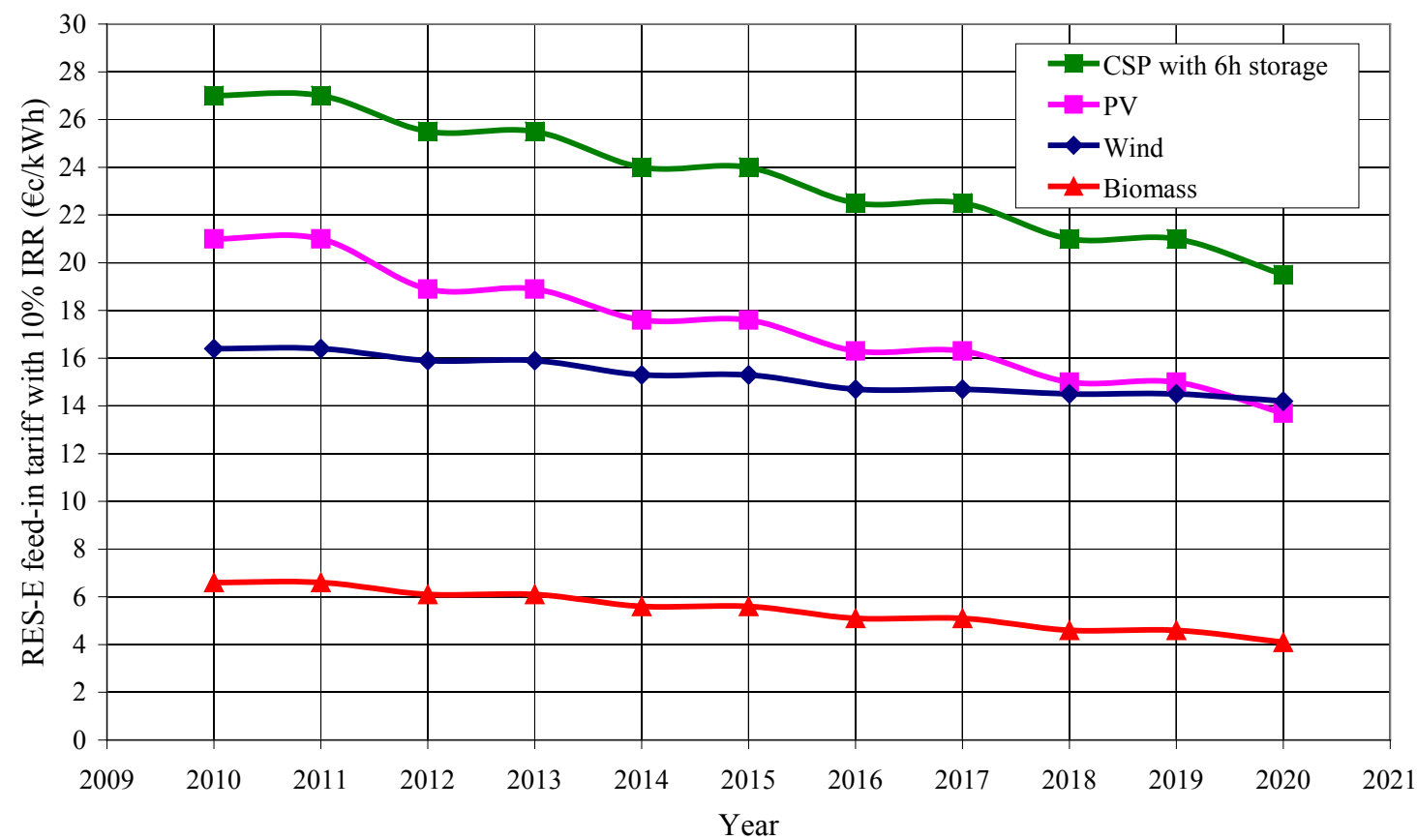

Figure 2: Optimum RES-E FiTs for 10\% IRR

The results concerning the estimated overall cost increase in the electricity sector for the promotion of RES-E technologies, for the period 2010-2020 are illustrated in Figure 3. This is a differential cost increase compared of each RES-E scenario to the results obtained with the BAU scenario and takes into account the following factors: (a) fuel consumption since by increasing RES-E penetration fuel consumption is reduced, (b) $\mathrm{CO}_{2}$ emissions since by increasing RES-E penetration $\mathrm{CO}_{2}$ EU ETS trading cost is reduced and (c) conventional power system since by increasing RES-E penetration the conventional power system operating cost is increased due to the increased requirements of conventional reserve capacity and due to the operation of conventional plants at lower capacity factors.

The overall cost increase in the electricity sector is expected to be recoverable through the electricity bills partly as a direct cost (RES-E levy) and partly as an indirect cost (utility RESE purchasing price and/or $\mathrm{CO}_{2}$ trading auctioning). For comparison purposes the following two cases are examined: (a) RES-E investments with no profit (i.e., IRR at $0 \%$ ) and (b) RES$\mathrm{E}$ investments with profit (i.e., IRR at 10\%). The overall results concerning the differential electricity unit cost from BAU scenario (no RES-E penetration) for the different RES-E penetration scenarios investigated are illustrated in Figure 3. For example, for 15\% RES-E penetration, in the case of investments with no profit (i.e., IRR at $0 \%$ ) the overall additional cost will be $0.79 € \mathrm{c} / \mathrm{kWh}$ (in real prices), however, in the case of investments with FiTs with 
IRR at $10 \%$ the overall additional cost will be $1.28 € \mathrm{c} / \mathrm{kWh}$ (in real prices). For the latter the required level of RES-E levy in the electricity bills need to increase from the current level of $0.44 € \mathrm{c} / \mathrm{kWh}$ to $0.53 € \mathrm{c} / \mathrm{kWh}$.

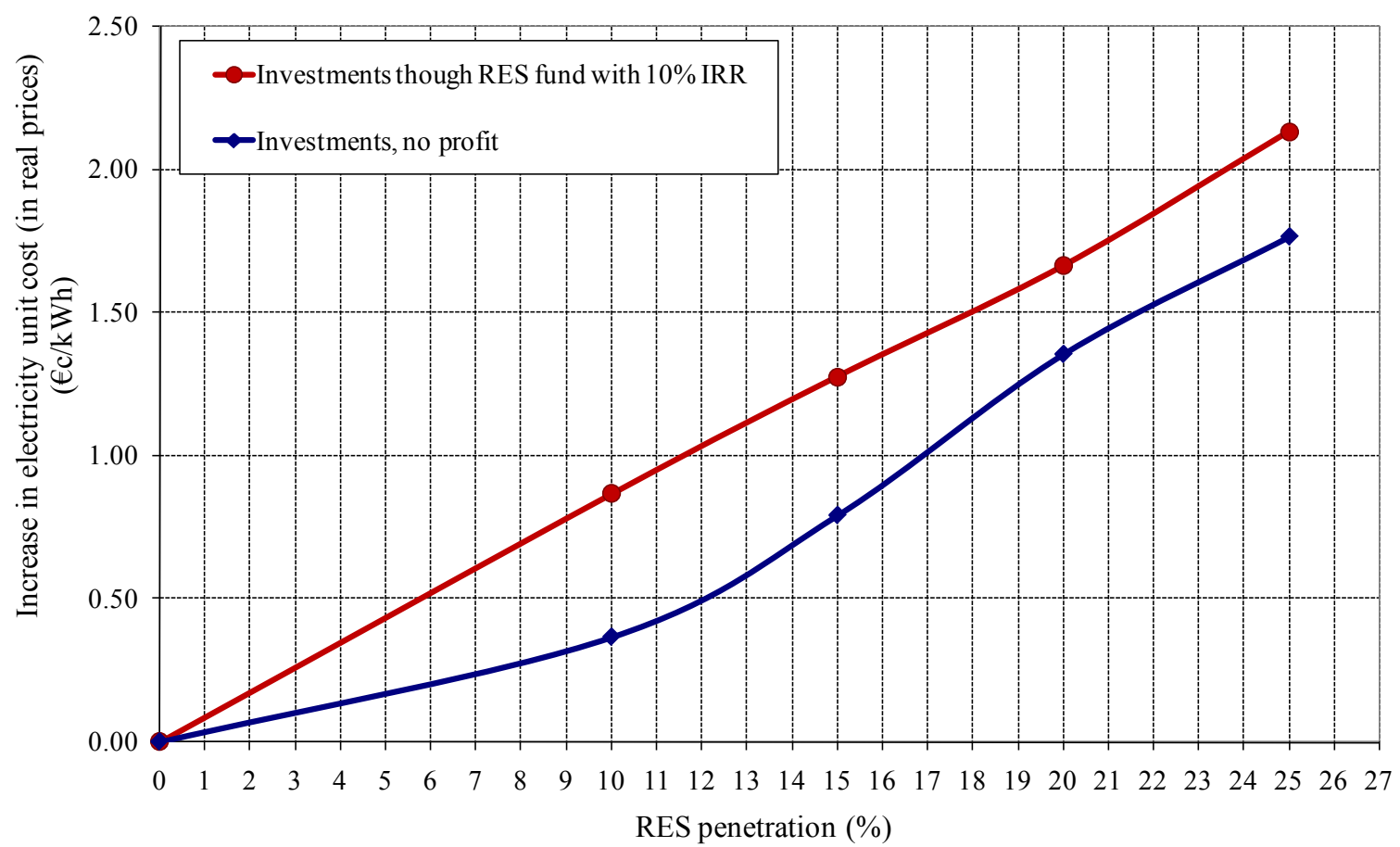

Figure 3: Overall results for the differential electricity unit cost from BAU for RES-E promotion (in real prices)

\section{Conclusions}

The main purpose of this work was to assess the unavoidable increase in the cost of electricity of a generation system by the integration of the necessary RES-E technologies for the EU Member States to achieve their national RES energy target. The optimization model developed uses a GA technique for the calculation of both the additional cost of electricity due to the penetration of RES-E technologies as well as the required RES-E levy in the electricity bills in order to fund this RES-E penetration. Also, the procedure enables the estimation of the level of the optimum FiT to be offered to future RES-E systems. Such decision support methodology for the optimum RES-E penetration cost level is of high importance not only from an economic point of view, but also from a political prespective since it can be used to help politicians to decide on the least cost RES-E penetration scenarios.

The applicability of the developed optimization model was applied to the small isolated power generation system of the island of Cyprus. The overall cost increase in the electricity sector for the promotion of RES-E technologies, for the period 2010-2020, was analyzed. This is a differential cost increase compared of each RES-E scenario to the results obtained with the BAU scenario and takes into account factors, such as, the fuel avoidance cost, the $\mathrm{CO}_{2}$ emissions avoidance cost, the conventional power system increased operation cost, etc. The overall results indicated that in the case of RES-E investments with IRR of $10 \%$ the cost of integration is higher compared to RES-E investments with no profit (i.e., IRR at $0 \%$ ) by $0.3 € \mathrm{c} / \mathrm{kWh}-0.5 € \mathrm{c} / \mathrm{kWh}$ (in real prices), depending on the RES-E penetration level. 


\section{References}

[1] European Commission, Renewable Energy Road Map - Renewable energies in the 21st century: building a more sustainable future, 2006, $\operatorname{COM(2006)~} 248$.

[2] European Commission, Barcelona Process: Union for the Mediterranean, 2008, $\operatorname{COM}(2008) 319$.

[3] European Commission, Commission Decision of 30 June 2009 establishing a template for National Renewable Energy Action Plans under Directive 2009/28/EC of the European Parliament and of the Council, 2009, 2009/548/EC.

[4] European Commission, Directive 2009/28/EC of the European Parliament and of the Council 23 April 2009 on the promotion of the use of energy from renewable sources and amending and subsequently repealing Directives 2001/77/EC and 2003/30/EC, 2009.

[5] Poullikkas A., I.P.P. ALGORITHM v2.1, S oftware for power technology selection in competitive electricity markets, 2006, (C) 2000 - 2006, User Manual.

[6] Poullikkas A., "Implementation of distributed generation technologies in isolated power systems", Renewable and Sustainable Energy Reviews, 2007, 11, pp. 30-56.

[7] Poullikkas A., "A decouple optimization method for power technology selection in competitive markets", Energy Sources, 2009, Part B, 4, pp. 199-211.

[8] Poullikkas A., 2009, "Economic analysis of power generation from parabolic trough solar thermal plants for the Mediterranean region - A case study for the island of Cyprus", Renewable and Sustainable Energy Reviews, 13, pp. 2474-2484.

[9] Poullikkas A., 2009, Introduction to Power Generation Technologies, NOVA Science Publishers, Inc., New York, ISBN: 978-1-60876-472-3.

[10]Poullikkas A., Hadjipaschalis I., Kourtis G., 2010, “The cost of integration of parabolic trough CSP plants in isolated Mediterranean power systems", Renewable and Sustainable Energy Reviews, 14, pp. 1469-1476.

[11]Wien Automatic System Planning (WASP) Package: A Computer Code for Power Generating System Expansion Planning Version WASP-IV with User Interface User's Manual, 2006, International Atomic Energy Agency, Vienna. 